\title{
ECOLOGICALLY BASED APPROACH TO COASTAL DEFENCE DESIGN AND PLANNING
}

\author{
Barbara Zanuttigh $^{1}$, Inigo J. Losada ${ }^{2}$ and Richard C. Thompson ${ }^{3}$
}

\begin{abstract}
Sustainability of coastal areas requires the development of a standard procedure for the selection of equitable defence solutions and the design optimization of existing defences in order to minimize the impact on the environment and maximize positive effects such as species biodiversity and structure colonization. The aim of this paper is to propose a combined method, based on numerical simulations and on collection of ecological data in the field, to provide indications for an environmental friendly construction of breakwaters. This method is applied and tested against the case study of Elmer, UK, where information on existing species and their abundance related to hydrodynamic effects induced by the breakwaters.
\end{abstract}

Keywords: sustainability; design; procedure; environment; numerical model

\section{INTRODUCTION}

Urbanization and human development are historically widespread and are of the leading causes of habitat and species loss in coastal waters (Airoldi and Beck, 2007).

Today approximately 22'000 $\mathrm{km}^{2}$ of the European coastlines are covered by urban marine structures such as marinas, breakwaters, and seawalls, and development is expected to increase further due to the adverse effects of climate change and construction of off shore renewable energy developments. In this frame it is evident the need of a strategic and sustainable defence planning strategy.

Coastal defences may attract and support assemblages of macroalgae, invertebrates, and fishes that are often extraneous to the native characteristics of the area and can affect the surrounding environment (Moschella et al., 2005; Burcharth et al., 2007). These in turn lead to a wide range of environmental effects such as shifts in community composition, and possibly also to excluding indigenous species, and may also cause an increase in invasive, nuisance or other undesirable species (Martin et al., 2005). In contrast, proper defence design and planning may promote the survival of commercially important species, (e.g. mussels, crabs, oysters, limpets, fishes, sea urchins, etc.), enjoyable for diving, snorkelling or bird-watching, or have a high conservation value (Airoldi et al. 2005, Martins et al. in press).

Scope of this contribution is to provide designers with a generally applicable methodology to plan sustainable coastal interventions. More specific objectives are: to provide evidence of the environmental impact of coastal defences on the environment and identify most relevant design parameters; to investigate the effects of different cross-sections; to propose an optimal design layout considering extension and mutual distance of the defences.

The paper briefly describes the site and its environmental conditions. Then the characteristics of the 2DV and 2DH models used for this analysis, COBRAS-UC and MIKE 21, are summarized and the numerical tests performed are presented.

The 2DV tests include three different cross sections: Elmer existing defence, a rocky homogeneous structure, and two similar geometries, a rocky structure with a core and a berm breakwater. Velocity profiles inside the structures are used to assess water recirculation, drag forces on the structure slope allow to identify the hydrodynamic fluxes that can drift colonizing organisms, residual wave agitation inshore the structure determines the degree of landward habitat protection. The comparison of these results for different layouts are discussed to identify the effects of structure geometry and complexity on the environment.

Based on the most suited configuration for the cross section and on the existing layout, two layouts characterised by different breakwater to gap length are examined by means of 2DH numerical modeling. Estimated waves and currents allow for instance to determine the inshore wave energy reduction, with the consequent level of beach and habitat protection, and the water residence time

\footnotetext{
${ }^{1}$ University of Bologna, DICAM, Viale Risorgimento 2, 40136 Bologna, Italy, barbara.zanuttigh@unibo.it

${ }^{2}$ Universidad de Cantabria, Environmental Hydraulics Institute, Av. Los Castros s/n, Santander, 39005 (ES) losadai@unican.es

${ }^{3}$ University of Plymouth, Marine Biology and Ecology Research Centre, Drake Circus, United Kingdom, R.C.Thompson@plymouth.ac.uk
} 
inside the protected cell to assess water recirculation and thus also water quality. Erosion and deposition trends allow to estimate if renourishment is necessary and, if it is, its quantity and frequency, but also to identify the level of disturbance to the assemblages.

The results of analyses and numerical modelling are finally combined to provide an integrated methodology for selecting the sustainable scheme.

\section{COASTAL DEFENCES AT ELMER, UK}

The Elmer study site (West Sussex, South coast of UK), lies on an approximately straight stretch of coastline, between Bognor Regis and Littlehampton (Fig. 1). A system of eight shore-parallel offshore breakwaters was constructed (1991-1993), and the area between these and the coast was nourished with sediment. The breakwaters vary in size, depending upon their location, and cover an overall extension of about $2 \mathrm{~km}$ (Tab. 1). Towards the East, the gaps are larger and the length of the breakwaters is shorter, to produce a smoother transition between the scheme and the open beach downdrift (King et al., 2000). A terminal rocky groyne to the East of the system (downdrift end) acts as the beach level regulator.

The breakwaters are round-headed with a slope of 1:2.5 at the head, each breakwater is approximately $6 \mathrm{~m}$ high with a slope of 1:1.5 on the landward side and 1:2 on the seaward side with a 4 $\mathrm{m}$ wide crest. The breakwaters are constructed from large $\left(1 \mathrm{~m}^{3}\right)$ blocks of mainly granite (Norwegian granite which is hard with low porosity) and some limestone. These large blocks make the breakwaters highly porous, and water flowed between the seaward to the landward sides within seconds.

Elmer is located within a macrotidal environment, with a semi-diurnal tide. The mean spring tidal range is approximately $5.3 \mathrm{~m}$, whereas the mean neap tidal range does not exceed $2.9 \mathrm{~m}$ maximum. Spring tidal ranges can reach up to $6 \mathrm{~m}$. Near bottom (approximately $30 \mathrm{~cm}$ above the bed) tidal currents over the area do not exceed $1 \mathrm{~m} / \mathrm{s}$ (on spring tides); they run in a general east-west direction in the offshore areas. The offshore structures are exposed completely at low tide and, during high water they do not become completely submerged.

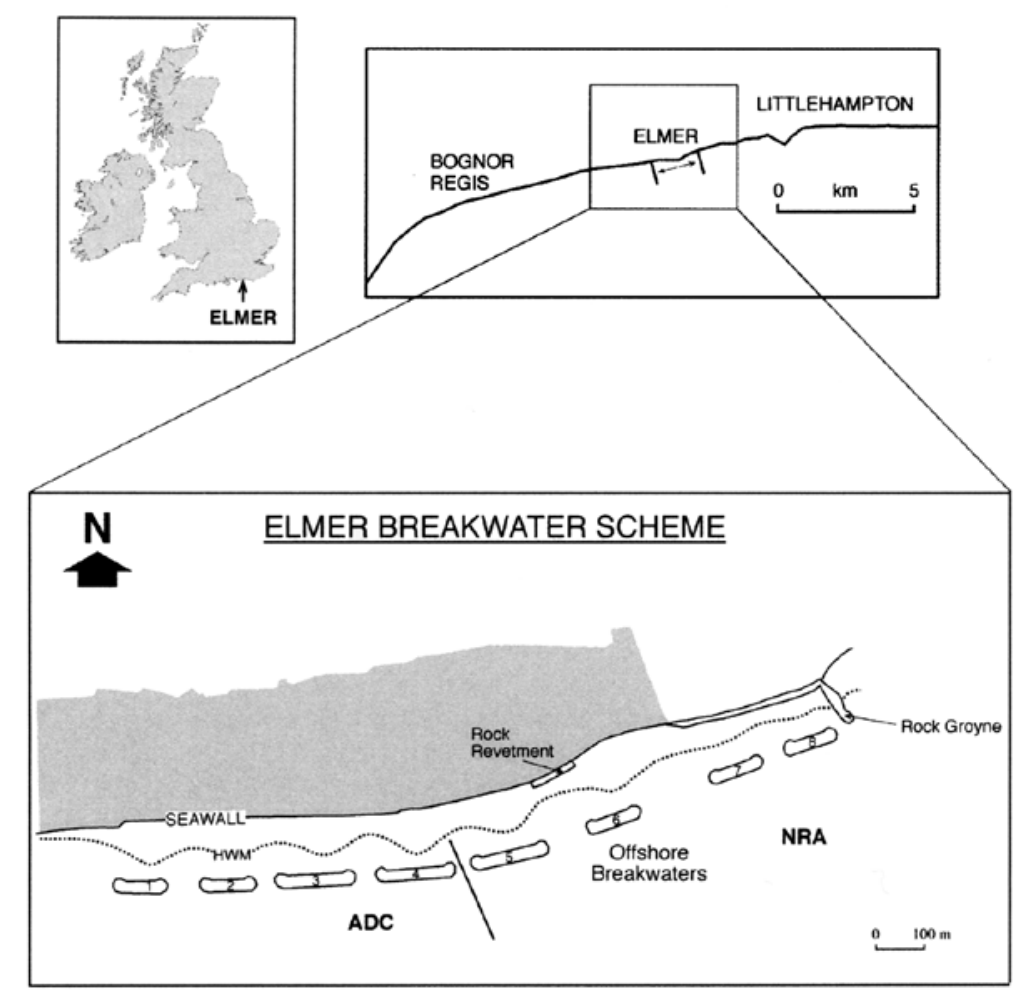

Figure 1. Location of Elmer site. From Burcharth et al. (2007).

The dominant wave direction is the Southwest; with 65\% of the waves approaching from within the segment $180^{\circ}$ to $220^{\circ}$, but with some $15 \%$ of the waves approach from the $100^{\circ}$ to $160^{\circ}$ 
(Southeast). Waves come from the sector of $180^{\circ}$ to $200^{\circ}$, with a significant wave height of up to $5.5 \mathrm{~m}$ and a wave period of about $7.5 \mathrm{sec}$ (Hydraulic Research, 1994). The sheltering effect of the Isle of Wight limits waves arriving from $220^{\circ}$ to $260^{\circ}$. In response to the gently sloping bathymetry at Elmer, the waves reach the coastline with very small angles of approach; this is especially characteristic of waves arriving from the southeast direction, which are more normally aligned to the shore.

The coastal plain generally comprises a poorly-consolidated layer of sand, exposed during low tides, with a $115 \mu \mathrm{m}$ median grain size. Shingle occurs on the upper part of the beach, on top of the thin sand veneer, median diameter of $20 \mathrm{~mm}$ (King et al., 2000). The longshore sediment transport in the area is to the east, with possible temporal reversal during long periods of Southeast winds and associated waves (Bray et al., 1995).

The LCS showed several effects on the surrounding environment (Burcharth et al., 2007), including accumulation of seaweed detritus on the landward side (Fig. 2), changes in the composition and abundance of sediment infaunal assemblages, increase in diversity of epibiotic species of the area and enhancement of juvenile fish. The composition of epibiota between the landward and the seaward sides of the breakwaters (Jonsson et al., 2006) is different, being the macroalgae (Fucus and Ulva) absent on the seaward side (Ulva here occurred on some limpet shells) and the abundance of limpets (Patella vulgata) much lower on the landward side. The abundance of filter feeders (barnacles) is greater on the seaward side.

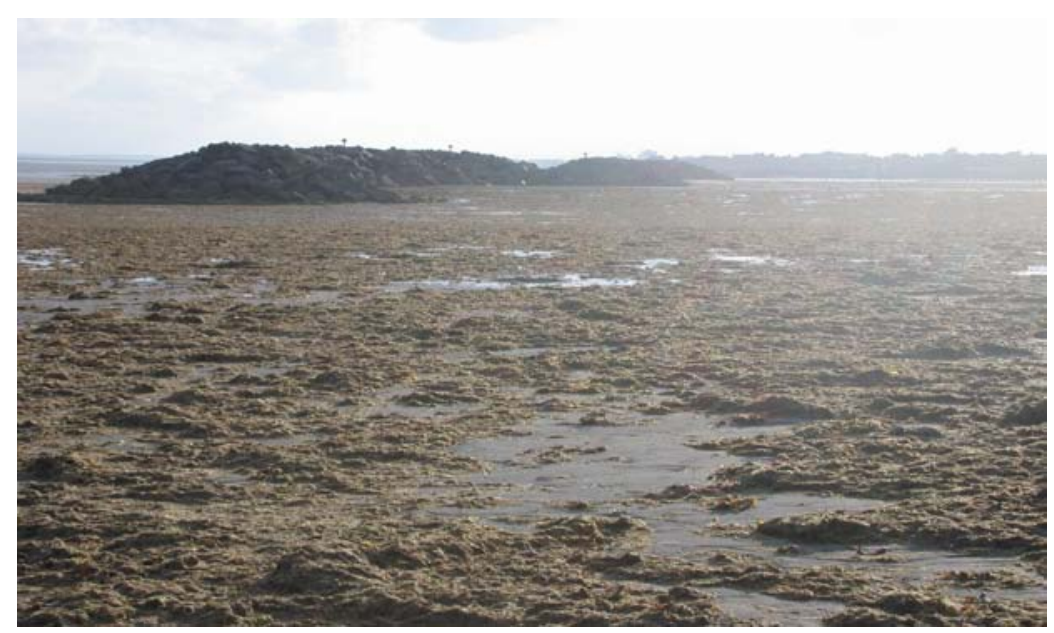

Figure 2. Accumulation of seaweed detritus inshore the barriers, Elmer, UK.

\begin{tabular}{|c|c|c|c|c|}
\hline Breakwater (\# as in Fig. 1) & $\mathrm{h}_{\mathrm{B}}, \mathrm{m}$ & $\mathrm{L}_{\mathrm{B}}, \mathrm{m}$ & $\mathrm{L}_{\mathrm{G}}, \mathrm{m}$ & $d_{s}, m$ \\
\hline 1 & 4.5 & 90 & 80 & 85 \\
\hline 2 & 4.6 & 90 & 00 & 79 \\
\hline 3 & 4.5 & 140 & 60 & 75 \\
\hline 4 & 4.5 & 140 & 60 & 77 \\
\hline 5 & 4.6 & 140 & 44 & 88 \\
\hline 6 & 4.6 & 80 & 100 & 54 \\
\hline 7 & 3.0 & 80 & 100 & 68 \\
\hline 8 & 3.0 & 80 & 80 & 38 \\
\hline
\end{tabular}

Rock pools (scales of 10-100 cm) had on average twice the number of species found on adjacent, freely draining parts of the LCSs. This difference was mainly determined by the absence, on open rock, of organisms such as sponges, hydroids, ascidians, small fish and prawns, which are very sensitive to desiccation stresses. Diversity was positively correlated with pool depth and hence the volume of the rock pools but not with the total surface area of the pools.

The building material used for LCS construction can also indirectly affect the epibiota, primarily through its surface complexity, which in turn depends on the intrinsic physical and chemical properties of the material. For example, epibiotic assemblages on sand bags or smooth concrete units were 
generally less diverse than on natural rock. Carbonate rocks such as limestone weather faster than igneous rocks, becoming rougher after few years, with crevices, pits and deep fractures forming.

Based on a coupled statistics of waves and tides in the area, two wave and tide conditions were selected (Tab. 2) to represent both storm and almost calm conditions. These two wave attacks were chosen to analyse respectively maximum and minimum hydrodynamic fluxes which determine the critical conditions for the survival and attachment of organisms and the expected maximum and minimum water residence time in the protected cell.

\begin{tabular}{|c|c|c|c|c|}
\hline & $\mathrm{H}_{\mathrm{s}}, \mathrm{m}$ & $T_{p}, S$ & $\mathrm{~d}, \mathrm{~m}$ & $\mathrm{~L}, \mathrm{~m}$ \\
\hline Wave 1 & 4.3 & 10 & 4.6 & 70 \\
\hline Wave 2 & 0.8 & 6.4 & 4.0 & 44 \\
\hline
\end{tabular}

\section{DESIGN OF THE CROSS SECTION}

\section{DV Numerical tests}

Numerical simulations were carried out at prototype scale with the 2DV COBRAS-UC code developed by the University of Cantabria (Losada et al., 2008, Guanche et al., 2008). Simulations were run disregarding turbulence.

Three cross sections were examined (Figure 3): the first section reproduces the existing homogeneous LCS ('Structure 1'), then the cross section was modified to include

- $\quad$ a core, to test the effect induced by porosity decrease ('Structure 2');

- $\quad$ a berm at mean sea level ('Structure 3'), to verify the possibility to include intertidal habitats.

Main characteristics of the cross sections are:

- $\quad$ structure height and crest width, $h=6.0 \mathrm{~m}, \mathrm{~B}=4 \mathrm{~m}$;

- $\quad$ berm height and width, $\mathrm{h}_{\mathrm{b}}=3 \mathrm{~m}, \mathrm{~B}_{\mathrm{b}}=4 \mathrm{~m}$;

- $\quad$ off-shore and in-shore structure slopes $\mathrm{i}_{0}=1: 2, \mathrm{i}_{\mathrm{i}}=2: 3$;

- $\quad$ off-shore and in-shore up and down berm slopes $\mathrm{i}=1: 2$;

- $\quad$ average armour and core stone size $\mathrm{D}_{50}=1.5 \mathrm{~m}, \mathrm{~d}_{50}=0.2 \mathrm{~m}$;

- $\quad$ for the armour, porosity $n=0.42$; Forchheimer coefficients $\alpha, \beta, \gamma=200,0.8,0.34$; for the core, porosity $\mathrm{n}=0.42$; Forchheimer coefficients $\alpha, \beta, \gamma=200,0.8,0.34$. These values are based on simulations performed for similar structures (Zanuttigh et al., 2008).

In all tested conditions, the numerical flume is 400x20 m and a 1:100 foreshore starts at around one wave length from the wavemaker and ends at around one wave length from the structure toe. The gauges were in total 23: one is at the wave generation, three are in front of the structure at a sufficient distance to analyse incident and reflected waves, 14 are placed from the off-shore till the in-shore structure toe (to cover the whole fluxes and pressures in/over the structure), three are inshore the structure at a sufficient distance to analyse wave transmission. It is worthy to note that the simulations do not represent the beach to reduce channel length, since problems related to run-up on the beach or reflection from the beach are not of interest for the purpose of this paper.

The simulation period was set to 3'000 s for Wave 1 and 2'400 s for Wave 2, in order to represent at least 300 waves. Grid spatial resolution along wave direction and perpendicular to the bottom were respectively $\Delta x=0.4$ and $\Delta y=0.4$ for Wave $1, \Delta x=0.2$ and $\Delta y=0.1$ for Wave 2 . The number of grid cells was thus equal to $1101 \times 41$ for Wave 1 and $1801 \times 101$ for Wave 2 .

\section{Results of 2DV simulations}

An example of numerical results obtained by means of the 2DV code are shown in Figure 3 for Structure 1 and Structure 3.

Some of the results that can be obtained with the numerical model and may be useful for ecological purposes are summarized in Tab. 2:

- wave reflection at the structure toe to estimate possible scour and nuisance to barrier colonization,

- wave transmission inshore the structure to verify residual wave agitation on the structure in-shore side and thus protection of the landward habitat; 
- $\quad$ velocities inside the structure to provide water exchange and variation of hydrodynamic fluxes and consequent conditions for the feeding and life of different organisms, Fig. 4; the corresponding recirculation time across the structure $T_{R}$, is evaluated based on filtration velocities averaged over the water depth and average structure width;

- drag forces $F_{D}$ on structure slopes in order to evaluate which organisms can resist to maximum hydrodynamic actions (Denny 1995).
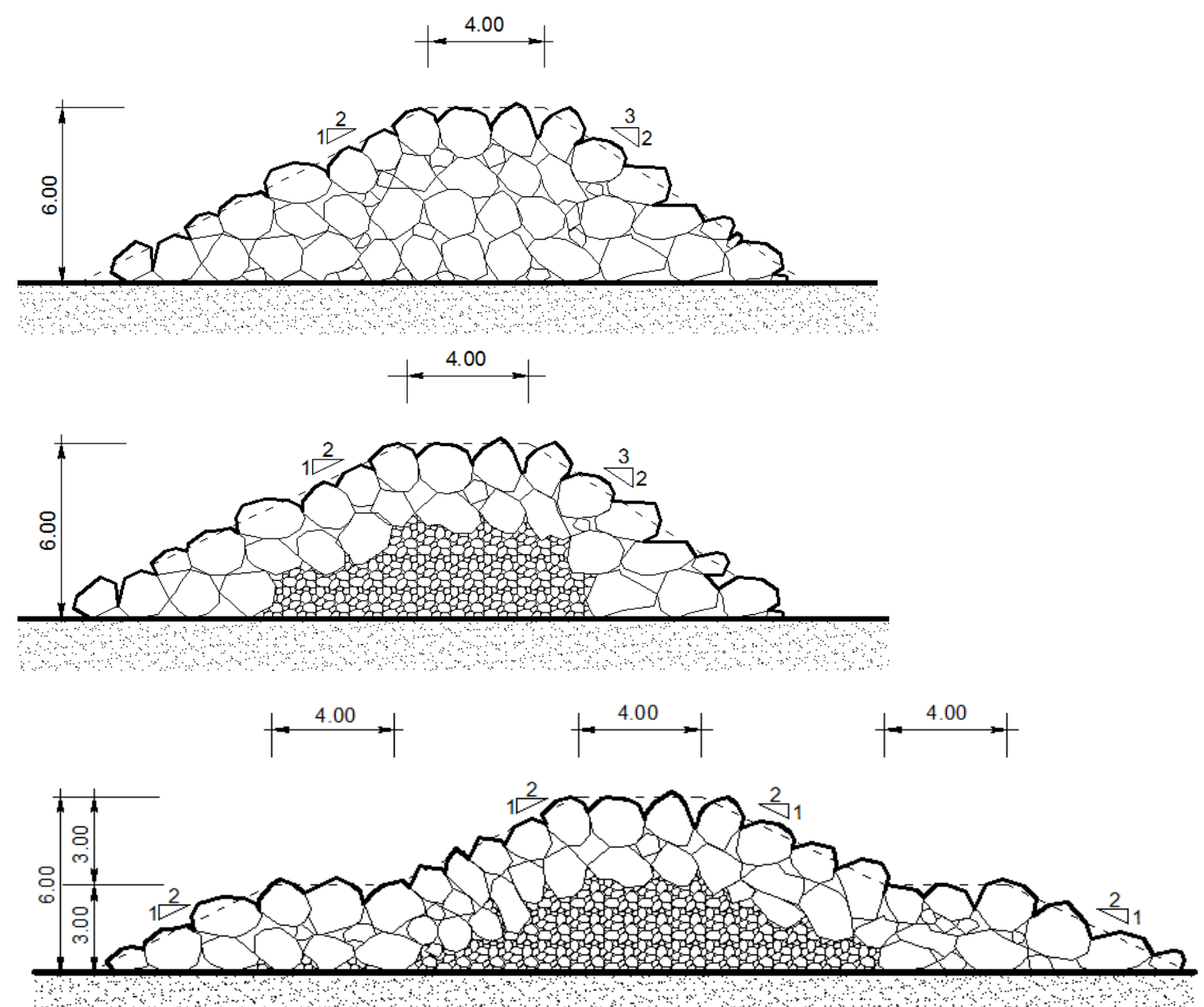

Figure 3. Tested structure cross sections with COBRAS, from top to bottom: homogeneous Elmer breakwater (structure 1), structure with core (structure 2), structure with core and berm (structure 3).

Drag forces are estimated on the off-shore slope, where velocities assume maximum values, and in correspondence of the maximum wave intensity (Wave 1). $F_{D}$ is calculated for algae, based on Eq. (6) in Boller and Carrington (2006) and on their indications given for Chondrus crispus,

$$
\mathrm{F}_{\mathrm{D}}=1 / 2 \cdot \rho \cdot u^{2} \cdot \text { Arep } \cdot \alpha_{\mathrm{U}} \cdot \mathrm{C}_{\mathrm{U}}=1.25 \mathrm{~N} \text {, }
$$

and for Fucus, based on Eq. (2) reported in Jonsson et al. (2006),

$$
\mathrm{F}_{\mathrm{D}}=\exp [10.7+1.62 \cdot \ln (u)+1.85 \cdot \ln (l)]=0.02-1.38 \mathrm{~N},
$$

where $u$ is the tangential velocity component averaged over flow depth at the structure toe, obtained from calculations as $1.75 \mathrm{~m} / \mathrm{s}$ for Wave $1 ; \rho$ is the sea water density, $1025 \mathrm{~kg} / \mathrm{m} 3$; $\mathrm{A}_{\text {rep }}$ is the representative algae area at of the holdfast at low configuration; $\mathrm{C}_{\mathrm{U}}$ is the drag coefficient as a function of velocity; $\alpha_{U}$ is the normalized area as a function of velocity; $l$ is the length of the Fucus that varies between 0.05 and $0.5 \mathrm{~m}$ (Jonsson et al., 2006). Values for $A_{\text {rep }}\left(20 \mathrm{~cm}^{2}\right), \alpha_{U}(0.5)$ and $C_{U}(0.8)$ are 
derived from the indications given in Boller and Carrington (2006) by supposing an algae population whose average length is about $0.1 \mathrm{~m}$.

By comparing the results as shown in Tab. 2, the presence of the core reduces wave transmission and increases the time necessary for water recirculation (lower velocities across the structure, Fig. 4). These effects are much more marked if a berm is included, due to the high dissipation induced by breaking on the seaward berm crest. Thanks to the macrotidal environment, in any event the strong reduction of wave transmission is critical for water exchange landward the structures. Indeed what is affected is water exchange through the structure, but is doubtful the effect on the possible presence of organisms within and inside the rocky blocks.

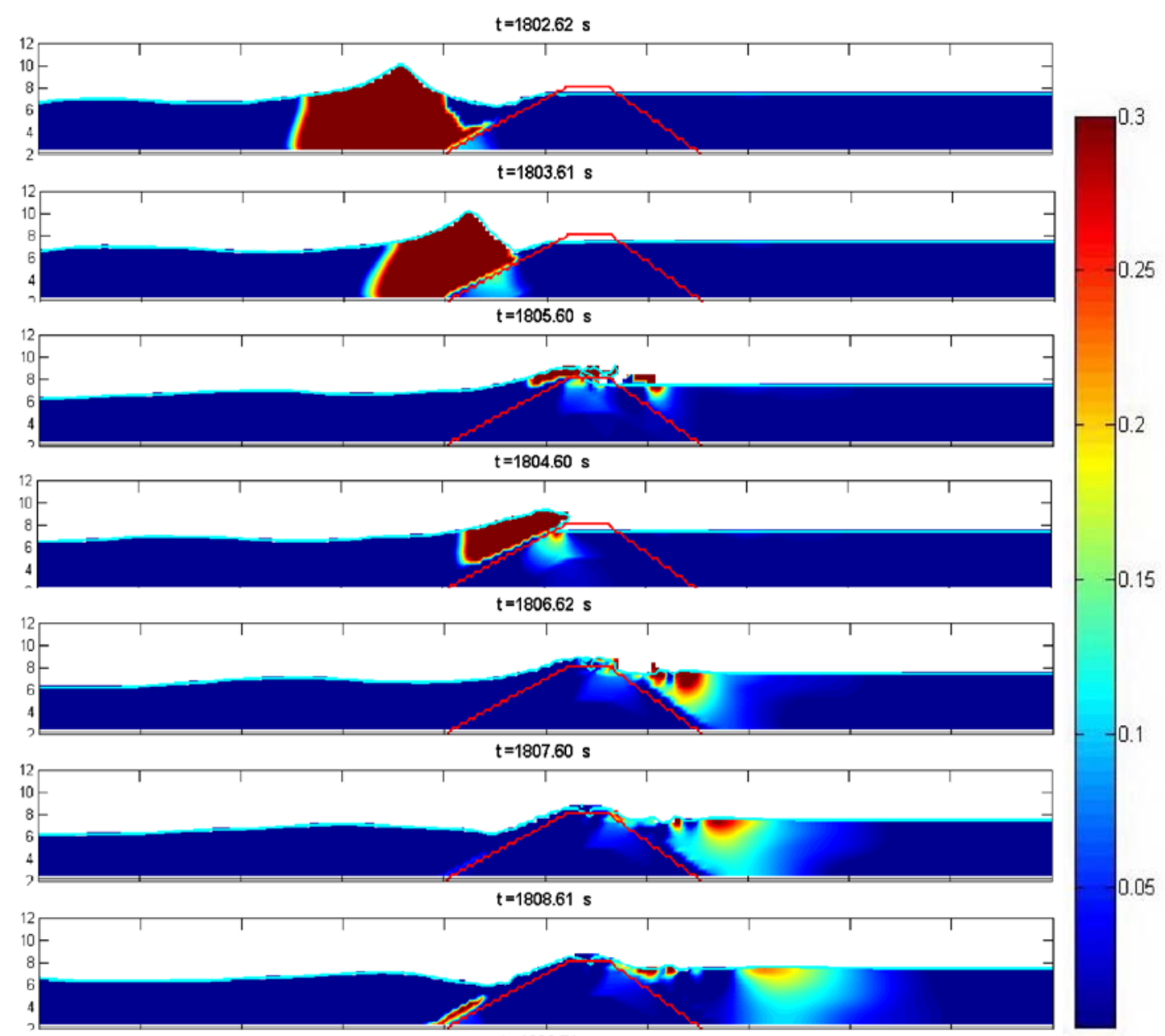

Figure 4. Velocities across the structure obtained by 2DV COBRAS code, structure 1, Wave 2.

\begin{tabular}{|c|c|c|c|c|}
\hline Section 1 & $\mathrm{H}_{\mathrm{si}}, \mathrm{m}$ & $\mathrm{K}_{\mathrm{r}}, \%$ & $\mathrm{~K}_{\mathrm{t}}, \%$ & $T_{R}, S$ \\
\hline Wave 1 & 2.57 & 58.5 & 3.3 & 206 \\
\hline Wave 2 & 0.57 & 36.5 & 1.2 & 2500 \\
\hline Section 1 & $\mathrm{H}_{\mathrm{si}}, \mathrm{m}$ & $\mathrm{K}_{\mathrm{r}}, \%$ & $\mathrm{~K}_{\mathrm{t}}, \%$ & $T_{R}, S$ \\
\hline Wave 1 & 2.59 & 59.1 & 3.8 & 245 \\
\hline Wave 2 & 0.57 & 37.1 & 1.5 & 3650 \\
\hline Section 3 & $\mathrm{H}_{\mathrm{si}}, \mathrm{m}$ & $\mathrm{K}_{\mathrm{r}}, \%$ & $\mathrm{~K}_{\mathrm{t}}, \%$ & $T_{R}, S$ \\
\hline Wave 1 & 2.59 & 51.6 & 2.1 & 328 \\
\hline Wave 2 & 0.57 & 29.7 & 1.1 & -- \\
\hline
\end{tabular}



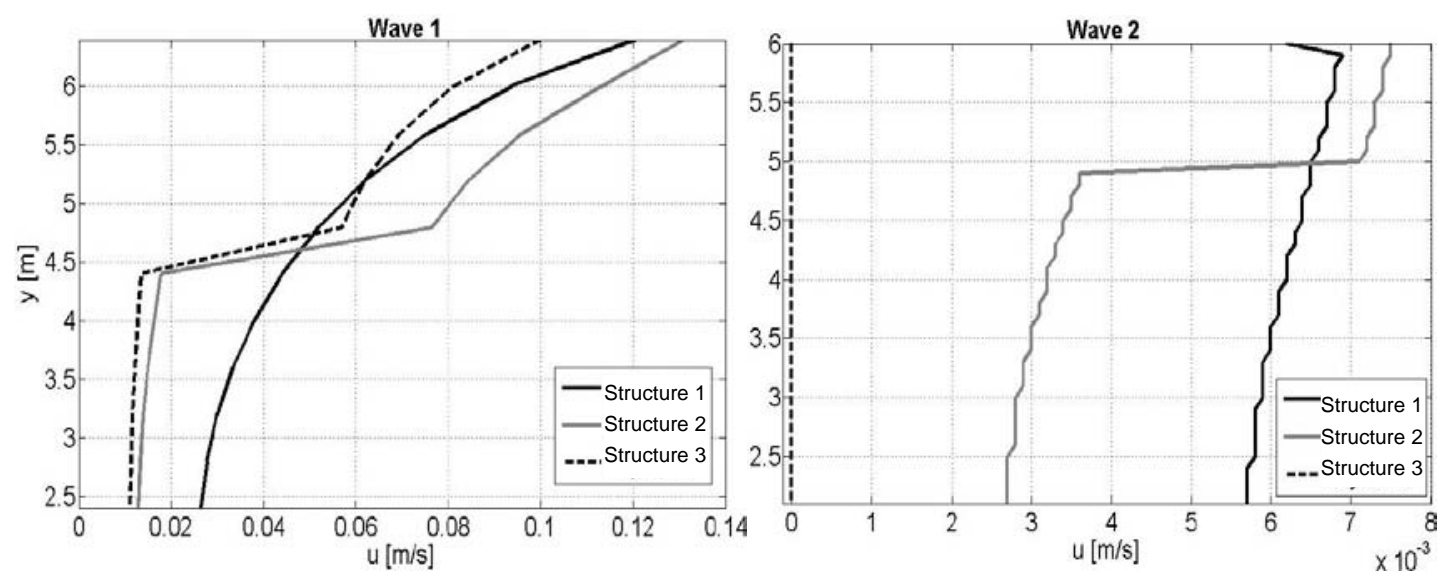

Figure 5. Velocity profiles (Wave 1 - left, Wave 2 - right) across the structure mid-section.

The high breaking on the berm reduces wave run-up on the structure, and thus increase the time for which organisms close to the structure crest can be exposed to air and light (the so called 'emersion stress', Hawkins and Hartnoll, 1985). Moreover, it produces high disturbance to the colonizing habitat on the seaward slope, a negative aspect which is not sufficiently balanced, due to the macrotidal environment, by the possibility to increase species diversity on the landward side.

For all tested conditions, wave reflection is very similar, and the reflection coefficient for Structure 1 is close to measured values in the field (Davidson et al., 1996). Wave reflection may lead to sediment suspension and local scour, that produce disturbance to marine organisms and may induce proliferation of invasive species.

\section{DESIGN OF THE LAYOUT}

\section{DH modeling}

Two layouts were selected for the purpose of this analysis considering two key elements: the ratio between breakwater and gap length and the distance from the shoreline. The two layouts were designed based on the characteristics of the existing defence system at Elmer:

- Layout 1: $\mathrm{L}_{\mathrm{B}}=140 \mathrm{~m}$, gap length $\mathrm{L}_{\mathrm{G}}=60 \mathrm{~m}$, distance from the shore $\mathrm{L}_{\mathrm{s}}=80 \mathrm{~m}$,

- $\quad$ Layout 2: $\mathrm{L}_{\mathrm{B}}=80 \mathrm{~m}, \mathrm{~L}_{\mathrm{G}}=80 \mathrm{~m}, \mathrm{~L}_{\mathrm{s}}=60 \mathrm{~m}$.

Based on indications from field surveys (Burcharth et al., 2007), the bottom is schematized as uniformly varying with foreshore slope 1:100 and with slope 1:20 from the structures till the shoreline.

In both layouts the cross section is represented as the homogeneous one (named 'Structure 1') already tested with the $2 \mathrm{DV}$ model. This choice is due to similar hydraulic performance and the better environmental performance proved by the results in Tab. 2 .

Numerical simulations presented here were performed with MIKE 21 MFM, a 2DH numerical modelling suite developed by DHI Water \& Environment \& Health. In particular, the morphodynamic simulations presented here were carried out with the Spectral Wave (SW) module, for propagating waves from offshore to in front of the structures, the Hydrodynamic (HD) module for simulating currents and the Quasi-3D Sediment Transport (ST-Q3) for representing sediment transport patters and intensities.

The SW module is a wind-wave model, which describes the growth, decay and transformation of wind-generated waves and swell in near shore areas. SW is a stationary, directionally decoupled parametric model. It and takes into account the effects of refraction and shoaling, local wind generation, energy dissipation due to bottom friction, and wave breaking, and wave-current interaction. The basic equations in the model are derived from the conservation equation for the spectral wave action density and are solved using an Eulerian finite difference technique. Wave breaking is represented by means of Battjes and Janssen model (1978).

The HD module solves the full time-dependent non-linear equations of mass and momentum balance. The solution is obtained using an implicit ADI finite-difference second-order accurate scheme, see e.g. Abbott et al. (1973) for details. 
The ST-Q3 module calculates the rates of non-cohesive sediment transport for both pure current and combined waves and current situations, on the basis of the hydrodynamic conditions that correspond to a given bathymetry.

The model parameters are chosen in the perspective of obtaining accurate results within a reasonable computational time. The modules are linked in the simulation so that currents are generated by waves, but also waves propagate on a varying depth depending on the levels calculated in HD module and the bathymetry is updated in time based on wave and current fields.

In particular in the SW module, the following settings are adopted:

- $\quad$ directionally decoupled, quasi-stationary, low-order integration scheme;

- $\quad$ variable Nikuradse roughness for sandy bottom and structures (respectively $0.05 \mathrm{~m}$ and $2.0 \mathrm{~m}$ );

- $\quad$ default breaking parameters for Battjes \& and Jannssen (1978) model: $\gamma_{1}=1.0$ (controls steepness breaking), $\gamma_{2}=1.0$ (controls depth limited breaking) and $\alpha=0.8$ (controls breaking dissipation rate);

- $\quad$ constant input waves at the off-shore boundary, based on wave attacks in Tab. 1;

- $\quad$ water level variations from HD simulations.

In the HD module, the following choices were made:

- low-order time and space integration scheme;

- $\quad$ variable Manning roughness coefficient roughness for sandy bottom and structures (respectively $30-50 \mathrm{~m}^{1 / 3} / \mathrm{s}$ and $14 \mathrm{~m}^{1 / 3} / \mathrm{s}$ );

- $\quad$ Smagorinsky formulation for eddy viscosity;

- $\quad$ wave radiation stresses from SW simulations;

- $\quad$ constant input water level at the off-shore boundary, based on Tab. 1.

In the ST-Q3 module:

- $\quad$ sand transport is determined by the combination of waves and currents;

- $\quad$ the sediment transport table is calculated based on Doering and Bowen theory (1986);

- $\quad$ structures are non-erodible;

- bottom sediments are characterized by the average particle diameter $D_{50}=0.15 \mathrm{~mm}$.

The weaknesses of the numerical results are mainly related to the missing representation of wave transmission in presence of zero freeboard and emerged structures. An attempt to represent wave overtopping (and rip currents) also in emergent conditions considered the placement of pairs of sources and sinks with a given overtopping discharge (Zanuttigh and Lamberti, 2006). This same approach was adopted to reproduce wave overtopping in case of Wave 1, both for Layout 1 and 2 . In case of Wave 2, based on the very low values of $K_{t}$ obtained by the 2DV simulations, the error induced by missing overtopping can be considered negligible for the purpose of representing residual wave agitation inshore the barriers.

\section{Results of 2DH simulations}

Figures 6-11 present, for each layout:

- $\quad$ bathymetry of the intervention;

- $\quad$ bottom level variation in the 6-hours of simulation and total sediment transport;

- $\quad$ extreme wave field for Wave 1;

- current field for Wave 1 to identify the areas where greater set-up is induced (set-up in colour scale; current speed intensity and direction as vectors) and Wave 2 to identify the more stagnant regions (speed intensity in both colour scale and vectors.

Figure 10 shows in details current speeds around the structure at fixed positions seaward, landward and at the roundheads to detail the exposure of the colonizing organisms.

A summary of numerical results useful for ecological purposes is reported in Table 3, which presents

- $\quad$ average values of wave agitation to estimate the protection degree offered to the habitat in the two conditions; the comparison is done through the average values in the protected are of the transmission coefficient $\mathrm{K}_{\mathrm{t}}$;

- average and extreme values of current velocities around the structures, to estimate living conditions for colonizing organisms;

- $\quad$ average and extreme values of current velocities inside the protected cell, to estimate living conditions for organisms placed on the soft bottom;

- $\quad$ average values of water residence time inside the protected area, which are obtained as average values of hydrodynamic flux balance to water volume ratio over the protected area. 


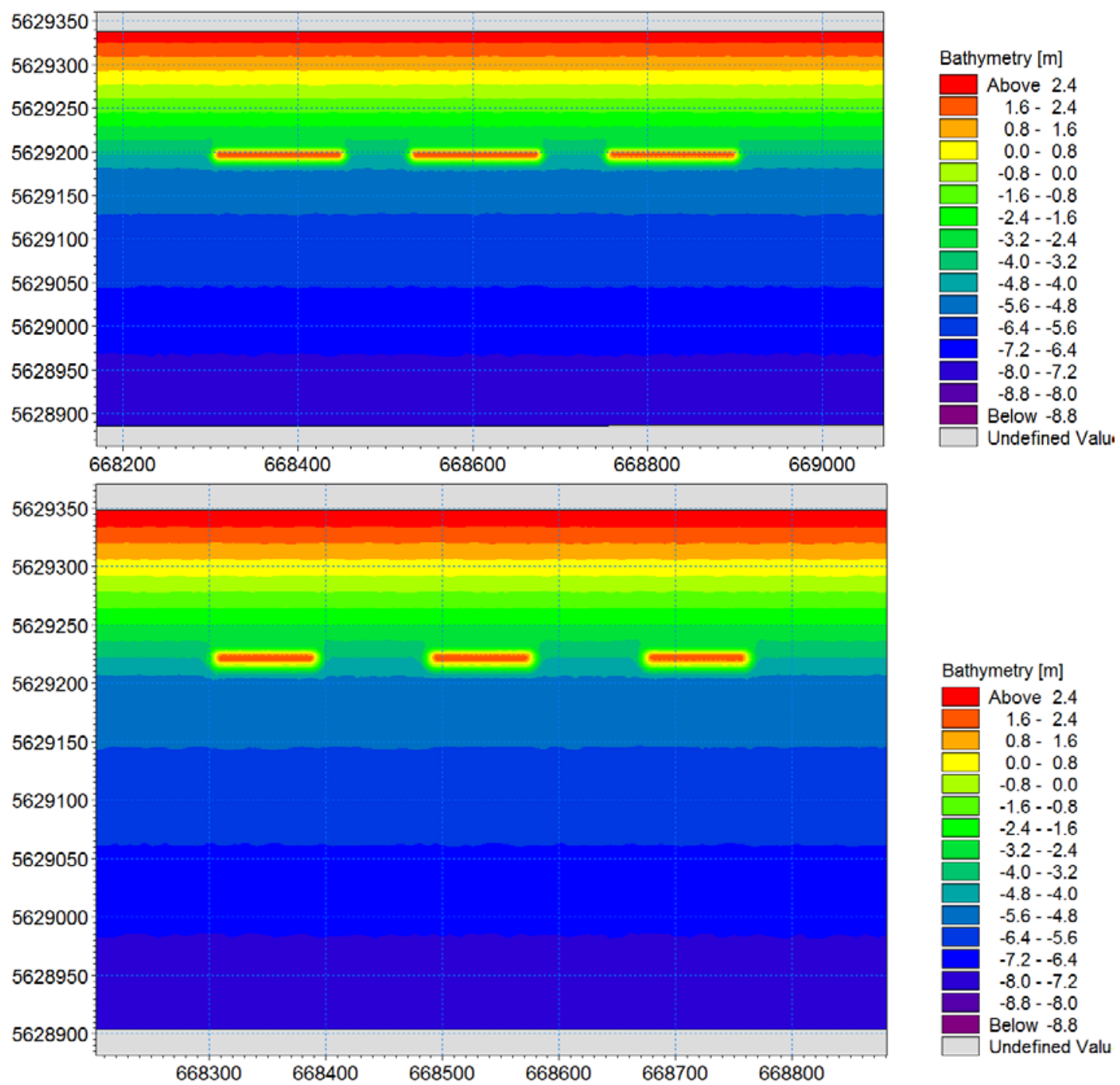

Figure 6. Bathymetry, Layout 1, top; Layout 2, bottom. Zero level corresponds to a sea level equal to $4.5 \mathrm{~m}$.

Wave agitation. The structures are efficient in reducing incident wave energy on the beach. Reduction of incident wave height on the shore is responsible for two opposite effects: one, positive, the reduction of offshore sand transport from the emergent beach; another, negative, the landward reduction of wave agitation that inhibits deposition of fine sediments.

Transmitted wave heights inshore the barriers (middle section) are in the range $40-60 \% \mathrm{~m}$, the incident wave heights at the structure toe being $\mathrm{Hs}=2.95 \mathrm{~m}$ and 0.79 for Layout 1 and $\mathrm{Hs}=2.88$ and $0.79 \mathrm{~m}$ for Layout 2. Average wave transmission inshore the barriers is greater in case of Layout 2, due to the wider gaps. since for Waves 1 and $2 \mathrm{~K}_{\mathrm{t}}$ equals respectively 0.48 and 0.55 in case of Layout 2 and equals 0.33 and 0.38 in case of Layout 1.

The values of Kt are clearly not reliable for Wave 1, due to the missing representation of wave transmission above the crest. It is thus calculated again the transmission coefficient across the barriers for Wave 1 by means of Van der Meer et al. (2005) formulation (giving an almost equal value of 0.310.32) and then the average Kt is calculated as a weighted average on structure and gap length. It results $\mathrm{Kt}=0.49$ for Layout 1 and $\mathrm{Kt}=0.59$ for Layout 2 . Wave agitation thanks to the presence of gaps is thus quite high and avoids the formation of a lagoon-environment.

Set-up (Figure 8, Tab. 3). Set-up at the beach increases with increasing the beach protection level, and thus is greater for Layout 1 than for Layout 2. Indeed the difference between the two extreme values (reached fror Wave 1) is limited, being equal to $0.07 \mathrm{~m}$ : it is not expected any significant consequence of this difference from an ecological point of view. 
Currents (Figures 8 and 9 and 10, Tab. 3). Current intensities induced by the two configurations is similar both in the protected cell and around the structures, except for maximum current speed at the structures for Wave 1 that may reduce settlement and survival of some organisms. Difference in current speed for seaward and landward side are shown in Figure 10 and motivate the different composition of the habitat for both Layouts: macroalgae (Fucus and Ulva) are absent on the seaward side (Ulva here occurred on some limpet shells) and limpets (Patella vulgata) are abundant whereas they are much lower on the landward side. .

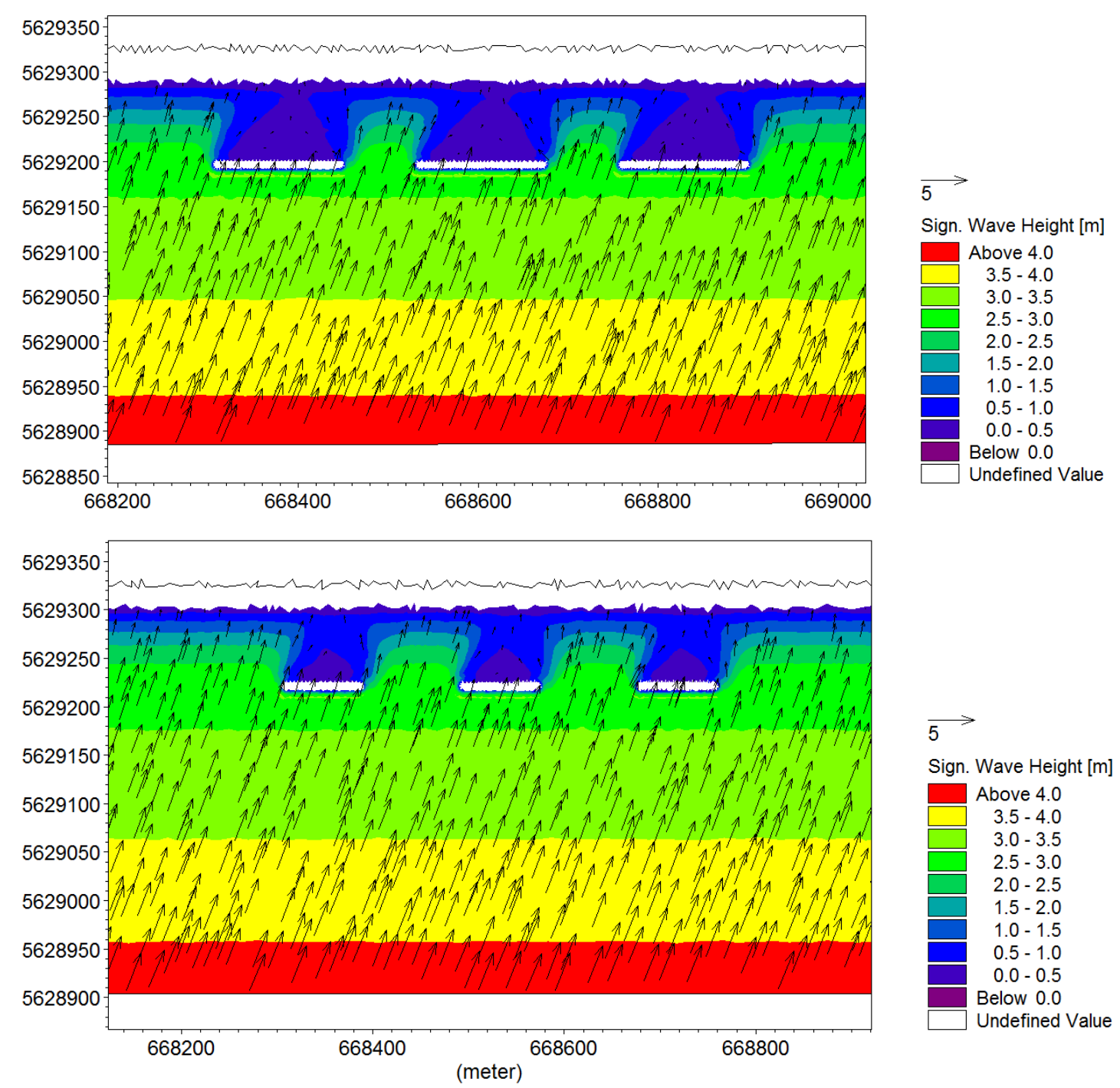

Figure 7. Results of wave height simulations on Layout 1, top; on Layout 2, bottom. Wave 1.

Sediment transport (Figure 11). The two layouts produce very similar erosive/depositional patterns under the typical storm, Wave 1 . There is a strong deposition seaward the barriers and inshore the gaps, which is more marked for Layout 2 providing a global accumulation tendency at the shoreline. Great erosion occurs seaward the gaps with the typical "tongue of flame" shape and inshore the barriers. The eroded areas are wider -but not deeper- in presence of wider gaps.

The erosive/depositional patterns are well defined so that -considering almost fixed in the area the wave obliquity for most part of the time- the colonizing habitat do not have to suffer alternative deposit and erosion at a given place.

Erosion areas are sufficiently far from the structure not to compromise their stability and thus not to give nuisance to colonizing organisms. The most relevant issue seems to be the great deposition 
seaward the structure and on the structure slope so that structures appear -as in prototype- to be partially submerged by sediments. This factor significantly affects the type, variety and number of colonizing assemblages.

Water mixing (Tab. 3). Considering the values of the residence time $\mathrm{T}_{\mathrm{RC}}$, it can be seen that in case of wider gaps the time needed for water recirculation in the protected area is more or less half than in case of narrower gaps.

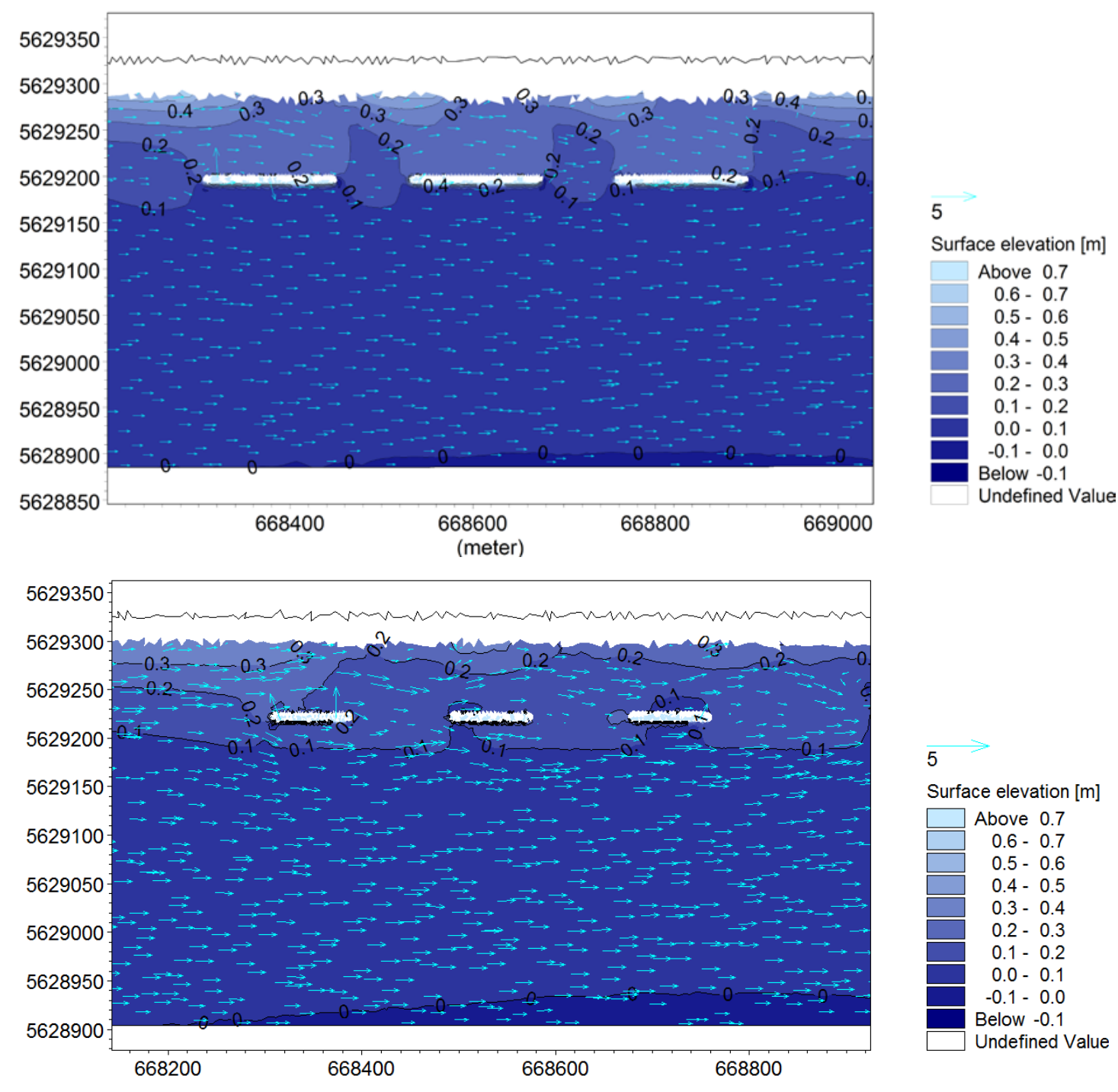

Figure 8. Water surface elevation (in colours) and current speed (in vectors). Wave 1. Top: Layout 1, bottom: Layout 2.

\begin{tabular}{|c|c|c|c|c|c|c|}
\hline Layout 1 & $\mathrm{H}_{\mathrm{si}}, \mathrm{m}$ & $\mathrm{K}_{\mathrm{tc}}, \%$ & $\mathrm{U}_{\mathrm{ms}}, \mathrm{U}_{\mathrm{ps}}, \mathrm{m} / \mathrm{s}$ & $\mathrm{U}_{\mathrm{mc}}, \mathrm{U}_{\mathrm{pc}}, \mathrm{m} / \mathrm{s}$ & $\mathrm{S}_{u c}, \mathrm{~m}$ & $\mathrm{~T}_{\mathrm{RC}}, \mathrm{min}$ \\
\hline $\begin{array}{l}\text { Wave } 1 \\
\text { Wave } 2\end{array}$ & $\begin{array}{l}2.88 \\
0.79\end{array}$ & $\begin{array}{l}49 \\
38\end{array}$ & $\begin{array}{l}0.75-7.6 \\
0.09-1.59\end{array}$ & $\begin{array}{l}0.94-1.79 \\
0.15-0.80\end{array}$ & $\begin{array}{l}0.24 \\
3.9 * 10^{-3}\end{array}$ & $\begin{array}{l}46 \\
249\end{array}$ \\
\hline Layout 2 & $\mathrm{H}_{\mathrm{si}}, \mathrm{m}$ & $\mathrm{K}_{\mathrm{tc}}, \%$ & $\mathrm{U}_{\mathrm{ms}}, \mathrm{U}_{\mathrm{ps}}, \mathrm{m} / \mathrm{s}$ & $\mathrm{U}_{\mathrm{mc}}, \mathrm{U}_{\mathrm{pc}}, \mathrm{m} / \mathrm{s}$ & $\mathrm{S}_{\mathrm{UC}}, \mathrm{m}$ & $\mathrm{T}_{\mathrm{RC}}, \mathrm{S}$ \\
\hline $\begin{array}{l}\text { Wave } 1 \\
\text { Wave } 2\end{array}$ & $\begin{array}{l}2.95 \\
0.79\end{array}$ & $\begin{array}{l}59 \\
55\end{array}$ & $\begin{array}{l}0.46-4.46 \\
0.08-1.18\end{array}$ & $\begin{array}{l}1.24-2.48 \\
0.23-0.81\end{array}$ & $\begin{array}{l}0.17 \\
2.4 * 10^{-3}\end{array}$ & $\begin{array}{l}25 \\
116\end{array}$ \\
\hline
\end{tabular}



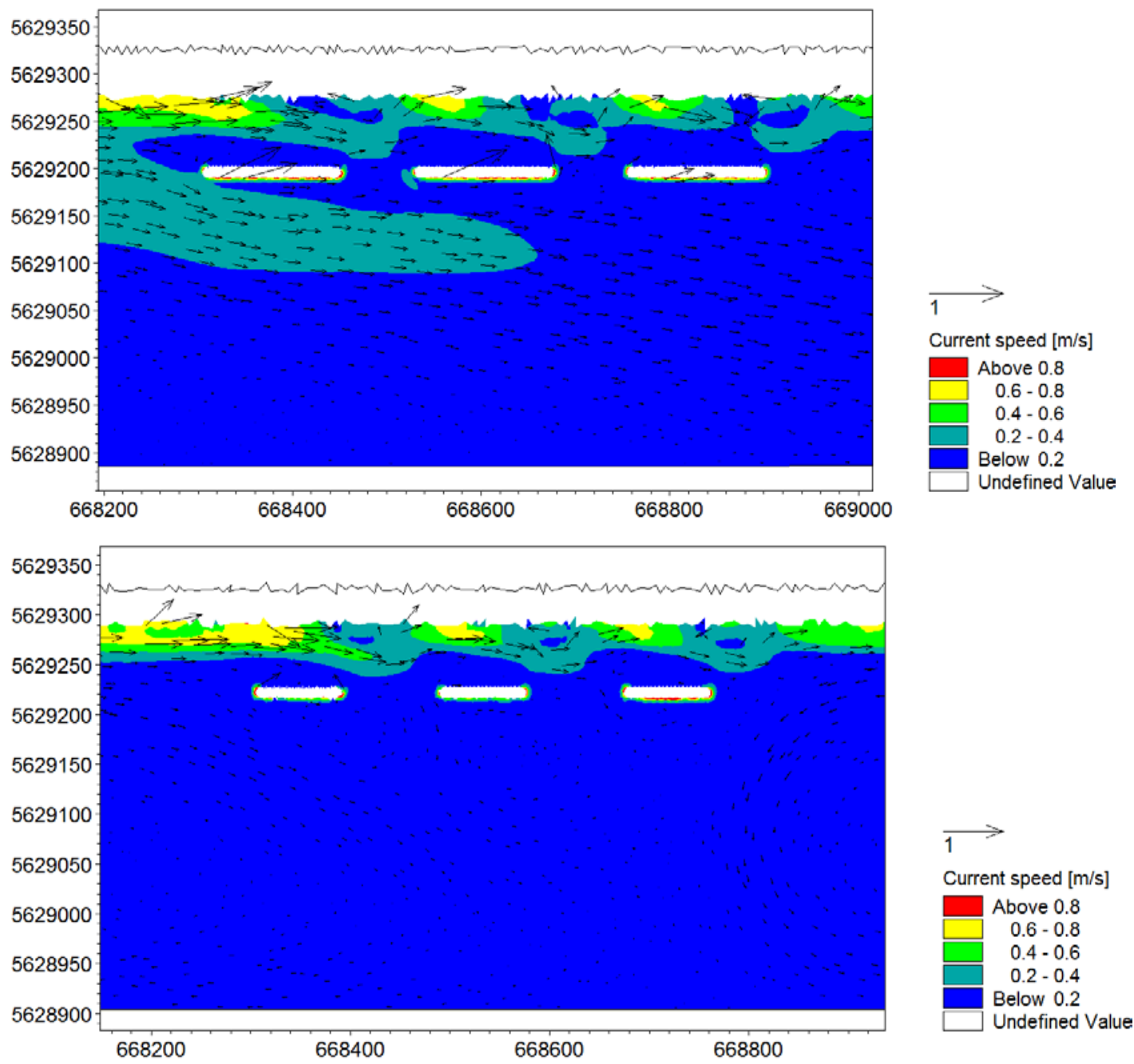

Figure 9. Current speed (in colours and vectors). Wave 1. Top: Layout 1, bottom: Layout 2.

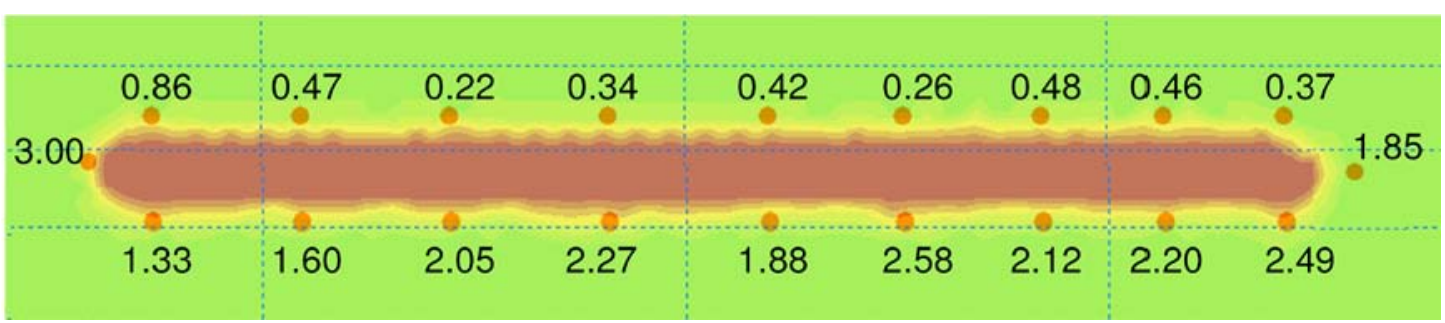

Figure 10. Distribution of the intensity of currents in $\mathrm{m} / \mathrm{s}$ for Wave 1 , Layout 1 (structure in the middle), in correspondence of the points shown in the scheme. Waves come from the bottom. 


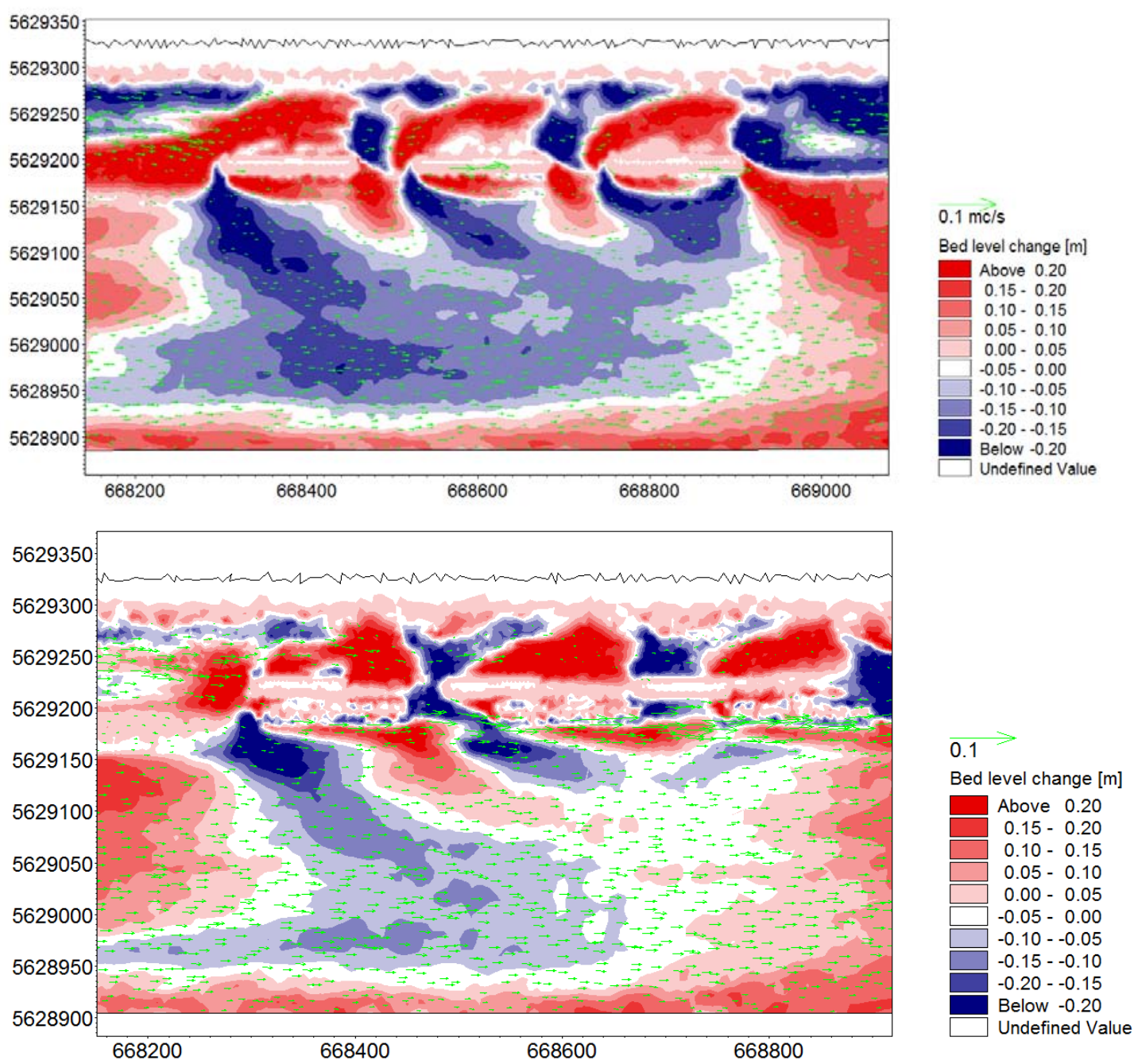

Figure 11. Bed level change (in colours) and sediment transport (in vectors) predicted after 6-hours storm, Wave 1. Top: Layout 1, bottom: Layout 2.

\section{DISCUSSION AND CONCLUSIONS}

After a preliminary selection of design alternatives, each alternative has to be examined and compared with respect to its technical, socio-economical and environmental performance. The use of numerical and physical models may help to predict the hydro-morphological consequences of each solution and their suitability to accomplish the design objectives.

The procedure here presented is composed by two steps: the first step is the design of the cross section geometry and consists of 2DV numerical modeling with COBRAS-UC that allows high resolution in space and time. The second step is the design of the layout and is performed by a depth and wave averaged model, MIKE 21.

Estimated waves and currents allow, for instance, evaluation of the following:

- $\quad$ the inshore wave energy reduction with the consequent level of beach protection;

- $\quad$ the water residence time inside the protected cell to assess water recirculation (and thus also water quality) for ecological purposes;

- $\quad$ the current patterns and intensities, in particular at gaps and roundheads, to verify bathing safety;

- the structure submergence/emergence due to waves and tide and its frequency, to check the possible dessication of organisms at the structure.

Estimated sediment transport allows, for instance, evaluation of the following:

- the global sand volume balance for the protected cell, in order to estimate if re-nourishment is necessary and, if it is, its quantity and frequency; 
- the formation of erosion areas that may produce structure instability, in order to redesign a proper protection or structure extension;

- the erosive/depositional patterns and their rate to identify the level of disturbance to the assemblages.

The modeling of the effects of Elmer breakwaters demonstrated that the design of high porosity structures, avoiding an inside core, is important for water recirculation across the structure.

The presence of a berm may introduce species diversity thanks to different structure levels, but indeed this positive effect can be balanced by high disturbance to the colonization on the seaward slope especially if the berm is at mean sea level and thus produces high breaking dissipation rates and strong reduction in wave run-up, with consequent increase of desiccation stress.

The simulation of different layouts through MIKE 21 helps in the estimate of the impact on the environment due to the following design features (selected for the macro-tidal Elmer environment).

- spatial arrangement of structures. Spatial arrangement (i.e. location, relative proximity to natural reefs and other artificial structures) of coastal defence structures is of great importance in influencing the type of benthic species that will colonise any novel structure, including the dispersal of invasive species. At Elmer, the relatively small variation of the distance between structures and shores (e.g. $20 \mathrm{~m}$, small for a macro-tidal environment) did not show any relevant effect on the barrier colonization.

- composition of the colonizing species. The composition of epibiota between the landward and the seaward sides of the breakwaters (Jonsson et al., 2006) is different, being the macroalgae absent on the seaward side and the abundance of filter feeders much lower on the landward side. This kind of colonization can be explained by means of the different wave and current conditions at the structure seward and leeward side (independently from differences in breakwater length, gap length, distance of the breakwaters from the shoreline).

- length of structures. At a local scale length of structures might affect hydrodynamics, particularly on the landward side. In case of emerged structures as Elmer, shorter structures should be preferred, as long structures create more sheltered conditions on the landward side to the detriment of water quality and sedimentary habitat: this fact can be particularly appreciated if one considers the different recirculation time induced behind the structures.

- distance between structures. In case of high emerged structures as in Elmer, currents at gaps are usually of low intensity and thus gap width is not a critical design parameter. Currents of moderate intensity do not lead to significant erosion at gaps and hence to risk of structure instability and disturbance of colonising organisms.

A general remark that cannot be accounted for in a realistic way (without proper calibration) by numerical models is the type and size of material used to build the structures that will affect the development of the epibiota.

In particular, if the structures are built with materials that are not typical of the area (e.g., as in Elmer, the Norwegian granite in an area of limestone bedrock) this may affect the local distribution of species, providing suitable substrata for species that would normally be rare or absent in the area, including invasive species. Therefore the same or similar stone materials typical of the area should be used. Carbonate rocks for instance are softer and are more easily weathered and bioeroded, leading to a more complex topography (crevices, small pits) which enhance colonisation and growth by algae and marine invertebrates.

Large pores among blocks allow greater water flow through the structures and increase water mixing on the landward side, thus reducing impacts on sediments and water quality. In addition, small pores can be easily filled blocked by growth of marine organisms such as mussels and polychaetes, which trap sediment thus further reducing porosity.

\section{ACKNOWLEDGMENTS}

The support of the European Commission through FP7.2009-1, Contract 244104 - THESEUS ("Innovative technologies for safer European coasts in a changing climate"), is gratefully acknowledged. 


\section{REFERENCES}

Airoldi L., Abbiati M., Hawkins, Jonsson P.R., Martin D., Moschella P., Thompson R. and P. Åberg, 2005. “An ecological perspective on deployment and design of low crested structures”, Coastal Eng., 52 (10), 1073-1087.

Boller, M. L. and E. Carrington 2006. "The hydrodynamic effects of shape and size change during reconfiguration of a flexible macroalga”, The Journal of Experimental Biology 209, 1894-1903.

Burcharth H. F., Hawkins S., Zanuttigh B. and A. Lamberti, 2007. Environmental Design Guidelines for Low Crested Coastal Defence Structures, Elsevier.

Davidson, M. A., Bird, P.A.D., Bullock, G.N. and D.A. Huntley, 1996 A new non-dimensional number for the analysis of wave reflection from rubble mound breakwaters, Coastal Eng., 28, 93- 120.

Denny, M. 1995. Predicting physical disturbance: mechanistic approaches to the study of survivorship on wave-swept shores. Ecological Monographs, 65, 371-418.

Guanche, R., Losada, I.J. and J. L. Lara, 2008. “An integrated approach to the analysis of coastal structures at prototype scale using COBRAS-UC”, Proc. 31st Int. Conf. on Coastal Eng., in press.

Hawkins, S. J., and R. G. Hartnoll. 1985. "Factors determining the upper limits of intertidal canopyforming algae.” Marine Ecology Prog. Series, 20, 265-272.

Jonsson, P., Granhag, L., Moschella, P., Aberg, P., Hawkins, S. J. and R. C. Thompson, 2006. "Interactions between wave action and grazing control the distribution of intertidal macroalgae", Ecology, 875, 1169-1178.

King D.M., N.J. Cooper, J.C. Morfett and D.J. Pope, 2000. “Application of offshore breakwaters to the UK: a case study at Elmer beach”. Journal of Coastal Research, 16, 172-187.

Losada, I.J., Lara, J.L., Guanche, R., Gonzalez-Ondina, J.M. 2008. "Numerical analysis of wave overtopping of rubble mound breakwaters”. Coastal Eng., 55 (1), 47-62.

Martin, D., Bertasi, F., Colangelo, M.A., Frost, M., Hawkins, S.J., Macpherson, E., Moschella, P.S., Satta, M.P., Thompson, R.C., deVries, M. and Ceccherelli, V.U., 2005. "Ecological impacts of low crested structures on soft bottoms and mobile infauna: how to evaluate and forecast the consequences of an unavoidable modification of the native habitats”. Coastal Eng., 52 (10), 10271051.

Moschella, P., Abbiati, M., Aberg, P., Airoldi, L., Anderson, J.M.,Bacchiocchi, F., Dinesen, G.E., Gacia, E., Granhag, L., Jonsson,P., Satta, M.P., Sundelof, A., Thompson, R.C., Hawkins, S.J., 2005. "Low crested structures as artificial habitats for marine life: what grows where and why?" Coastal Eng., 52 (10), 1053-1071.

Zanuttigh, B., Martinelli, L., Lamberti, A., Moschella, P., Hawkins, S., Marzetti, S. and Ceccherelli, V. U., 2005. “Environmental design of coastal defence in Lido di Dante, Italy”, Coastal Eng., 52 (1011), 1089-1125.

Zanuttigh, B., Van der Meer, J. W., Lykke Andersen, T., Lara J. L. and Inigo J. Losada, 2008. "Analysis of wave reflection from structures with berms through an extensive database and 2DV numerical modeling”, Proc. Coastal Eng. 2008. 